\title{
Five ethical doctrines for medical education
}

\author{
W T Tweel, Jr Department of Family Practice, Marshall University School of Medicine, Huntington, \\ West Virginia, United States
}

\begin{abstract}
Author's abstract
In recent years a relative barrage of journal articles has surfaced concerning the formal instruction of medical ethics in our medical schools.

Philosophical debates usually ensue over either the conspicuous absence (or, in some cases, the questionable need (I) (2)) of a formal ethics course, or the manner and method by which ethics is to be taught (3). There is, however, a paucity of literature as to what constitutes ethical medical 'pedagogy'. Germane is the principle that the physician-teacher should strive to be ethical both in what he or she teaches as well as the manner in which it is taught. This is also to view medical ethics from a broader perspective including the institution of instruction itself. The following discourse focuses upon five doctrines which would augment the medical curriculum by adding to the mere instruction of facts and skills a respect for the human values and rights innate to the practice of medicine.
\end{abstract}

\section{Five doctrines}

In constructing an ethical 'pedagogy', there must be devised particular doctrines which reach beyond the mere satisfaction of the teaching institution's educational goals. They should be based upon ethical principles that govern interpersonal relationships, maintain a respect for academic freedom, and reflect the utilitarian needs of society. The latter is increasingly relevant as medical education becomes a concern of consumerism and is partly financed from taxation. Already, government has controversially entered into the determination of how many and what types of physicians are to be educated in American schools (4), (5). With the above in mind, five basic doctrines are now somewhat boldly offered. Each of these is construed as an essential ideal, $i e$ in reality not always satisfiable, but necessarily never to be forgotten or overlooked. A discourse will then follow attempting to place each doctrine in contemporary perspective.

I) Educational goals leading to the graduation of a competent physician must be satisfied, recognising that competency will differ $(a)$ at the post-graduate level relative to which skills are germane to any given specialty and $(b)$ at the undergraduate level only beyond the core knowledge and skills established by each discipline.
2) A high standard of care must be both provided and taught.

3) The manner in which care is provided must be generally acceptable to both the provider (eg it meets the requirements of professional ethics) and the consumer (eg it is not dehumanising).

4) Cost effective medical practice is a necessary educational goal. This is not to be misconstrued as a call for elimination of research or a disrespect for academic freedoms.

5) The educational system should be concerned with the quality of interpersonal relationships involving the patient and all members of the health care team (eg doctor and patient, teacher and student, student and patient).

\section{GRADUATING THE COMPETENT PHYSICIAN}

An attempt either to define competencies or to construct methodologies ensuring competency is beyond the intended scope of this paper. Such a task remains an awesome and continuing necessity. For instance a study of surgical clerks at a teaching hospital showed a wide diversity in their learning experiences. Seven clerks had never been on teaching rounds, ten percent had not read general medical literature during their clerkship, and 30 percent had not researched a single patient's problems (6). Undoubtedly there are other areas in medical training deserving serious inquiry.

With regard to family practice, the American Academy of Family Practice has been strong in establishing for its residency programmes core curricula, such as the cooperative efforts between the American Academy of Family Physicians and both the American College of Obstetricians and Gynecologists and the American College of Cardiologists (7), (8). Similar and relative to the undergraduate curriculum in family practice is the Minnesota Academy of Family Physicians' Core Content of Knowledge for Family Practice (9). At Marshall University School of Medicine 'patientencounter logs' kept by family practice students allow faculty to monitor such parameters as profiles of patients seen, follow-up experiences, special procedures performed by the student, and so forth.

This first doctrine involves an important ethical issue for teaching institutions whose definitions and requirements of competency affect mode of care, costs of care and even continuity of care. Thus the Academy of Family Physicians for instance, was 
reported to be assisting four family practitioners in a suit against the American College of Surgeons. The latter had suspended a member surgeon who had turned post-operative care over to a 'less qualified' family physician. The results of this issue, not available at the time of writing, potentially affect care in small communities where visiting surgeons operate on patients in their home-town hospitals (IO).

\section{A HIGH STANDARD OF CARE}

One need only reminisce over the crowded emergency rooms and outpatient clinics which provide large teaching resources for our medical schools to remember that unique resources such as sophisticated equipment, scarce drugs, highly skilled personnel, or even specially funded screening programmes are not applicable to every patient treated within a teaching institution. The question here is not really whether medical schools are morally obliged or even capable of exemplifying a superior level of care, but how that level of care is to be comprehensive and exemplary. Certainly, such judgments cannot be made apart from ethical consideration.

\section{ETHICAL MODES OF CARE}

Traditionally, medical schools served as institutions of care to the financially indigent, who in return were expected passively to accept the ministrations of medical students. The advent of 'patient rights' and of federal regulations for the care of Medicaid and Medicare patients point up the ethical (and legal) dilemmas here. Private patients too are increasingly used for teaching and surgical patients may not, for instance, understand who will actually participate (and to what extent) in their operations. Kempner raises moral doubts about common current practices and suggests that patients should be given full information and should then choose between admission to a teaching or non-teaching hospital (II).

A less important problem but a common practice is the 'student-doctor' subterfuge. Students are referred to in a spectrum of nomenclature ranging from 'medical students' to simply 'doctor' and including the ambiguous term 'student-doctor'. Moreover students are often not distinguishable by the patient from residents and fellows. Tesleschi reports to his surprise that only 19 per cent of patients surveyed indicated any ill feeling at all about students being involved in their care. Furthermore, none of these patients would switch doctors simply because their doctor participated in a teaching programme. He then offers student tips on how they can become more acceptable to patients, without subterfuge, maturely recognising the right exercised by only a minority of patients to confine exposure of their problems and person to their personal physician (12).

Regarding the setting in which the educational process takes place, Plotz writes that the preceptorial or tutorial method, common in family practice programmes, has proved to be both an effective and ethical pedogogy. At the Downstate Medical Center, for instance patients are fully aware that they will be seen by a medical student and no medical decisions are made by the student without the advice and consent of the preceptor (13). At the Model Family Practice Center, Community Hospital, Santa Rosa, California, students see patients in a general medical clinic where every patient is presented to a board certified consultant. 'Patient acceptance is high (doctrine three), students feel that good quality medicine is practised (doctrine two), and charges are reasonable (doctrine four) (14).

It would seem, then, that effective teaching in a setting that preserves the integrity of the doctorpatient relationship is a realistic goal. The prerequisite is, of course, the establishment of definite policies on ethical relationships in patient care.

\section{COST EFFECTIVE MEDICINE}

One recalls that old cliche 'well, just for the sake of academics . . . Does the cost-effective practice of medicine in an institution of learning stifle academic freedom or is it, in fact, an essential example in medical education?

At a Hastings Center conference on 'Ethics and Health Cost Containment' Professor of Law, Charles Fried, suggested 'the one sure way to determine what the proper level of health care consumption is: by consumer choice (15). But consumers are not necessarily able to judge (nor expected to judge) whether the specific costs of sciences are befitting the need. Perhaps superior to questionably effective (and ethical ?) governmental controls such as limitation of physician manpower, coerced fields of specialisation, or indentured service in medically underserved areas, is a strong leadership role (by medical schools themselves) in actual instruction of cost-effective medicine. Such instruction may prove a more significant and perhaps the most ethical way of controlling health care costs.

Several models for this type of instruction have been proposed. Since I904 at the Medical College of Ohio a case study approach has been used where students estimate costs of treatments and conduct student chart audits. In 1977 the dimension of cost was added to exercises in clinical decision-making. This programme has increased cost-awareness by both students and residents at the Medical College of Ohio, but its long term effect is unknown (16).

Pilot programmes are already underway at the University of Michigan Medical School, Wayne State University School of Medicine, and Michigan State University College of Human Medicine. Specifically, Michigan State University College of Human Medicine proposed in 1979 a multidisciplinary course 'team taught by basic biological and behavioural scientists and faculty physicians' 
encompassing methods used in cost-effectiveness analysis and principles of decision theory (I7).

This is not to profess a 'cookbook' of cost-effective medicine. The suggestion however, is that there is a cost-effective approach to a given problem, in a given patient, in given circumstances which we are able and ought to teach.

\section{FOSTERING GOOD INTERPERSONAL RELATIONSHIPS}

According to Armondson, et al medical students become more cynical and less humanitarian during medical school. These changes are thought to be at least partly due to the medical school environment itself. In a survey of students at the University of Colorado School of Medicine, lack of personal freedom, feelings of dehumanisation, difficulty in getting to know faculty members well, being treated as immature and irresponsible, and having to perform excessive non-educational services were some of the major concerns expressed. 'In all likelihood, conflicts between students and their teachers increase over the four years of medical school in direct proportion to the students' matura tion.' A lack of respect for the students' growing maturity is felt to be the major factor here (18).

One cannot help but extrapolate the negative effect of such feelings upon the character of the relationships a young physician later forms with patients. Shüffel noted severe problems of hostility among medical students and hospital physicians alike. Demanding patients, for example, often trigger feelings of anger. Because of this, Shüffel has proposed 'guided attitudinal learning' which it is hoped will affect the manner in which physicians deal with angry, terminal, and excessively demanding patients. Medical training, says Shüffel, takes place under hostile conditions: matters are aggravated because the hostility is suppressed rather than expressed (19).

Recently the need for education concerning interpersonal attitudes has been recognised. Silbert even suggests that such attitudes as empathy, non-judgmental acceptance, and unconditioned positive regard and congruence are more effectively taught in a one-to-one setting rather than in the more traditional hospital-based teaching of large numbers of medical students (20). The University of Southern Illinois School of Medicine now teaches and evaluates 'affective skills' challenging instructors with such questions as 'does the student leave the patient feeling comfortable ?' or 'does the student show concern for the patient ?' (2I). Such teaching has now been adopted by a number of family practice programmes where the preceptorship or one-to-one teaching style enables the preceptor best to 'role-model' these skills.

\section{References}

(I) Brown L. Teaching of medical ethics. Fournal of the American Medical Association 1978 Jul 21; 240/3: 213.
(2) McKee F W. Teaching medical ethics. fournal of the American Association I979 Jan 5; 24I/I : 27.

(3) Siegler M. A legacy of Osler: teaching clinical ethics at the bedside. Fournal of the American Medical Association I978 Mar 6; 239/10: 951-956.

(4) Prediction of FP surplus meets with skepticism. Family Practice News I 980 Nov I; 10/21 : I, 56.

(5) Lewis R. Medical educators question manpower report's assumptions. American Medical News 1980 Nov $14: 3$, 10.

(6) Kennedy W R, Wile M Z. Medical students' activities on core surgical clerkships. Fournal of Surgical Research 1978 Dec 6; 25/6: 489-495.

(7) American Academy of Family Physicians. ACCAAFP Recommended Cardiology Core Curriculum for Family Practice Residents. Reprint 262. Kansas City, Mo: American Academy of Family Physicians.

(8) American Academy of Family Physicians. ACOGAAFP Recommended Core Curriculum and Hospital Practice Privileges in Obstetrics-Gynecology for Family Physicians. Reprint 26r. Kansas City, Mo: American Academy of Family Physicians.

(9) Admundson L. H Harvill L M, Roberts C M. The clinical services. In: Taylor $\mathbf{R}$ B, ed. Family medicine, principles and practice. New York Springer-Verlag, 1978: 40-57.

(I0) Delmar D. AAFP will assist four family physicians in suit against ACS. Family Practice News 1980 Nov I; 10/21: 1 .

(II) Kempner M L. Some moral issues concerning current ways of dealing with surgical patients. Bulletin New York Academy of Medicine 1978 Jul/Aug; 54/7: 657-664.

(12) Tedeschi $M$. The response of patients to students observing general practice. Australian Family Physician 1978 Sept; 9: Ir52-II55.

(13) Plotz C M. The family practice preceptorship: ethical concerns. Bulletin New York Academy of Medicine 1978 Jul/Aug; 54/7: 657-664.

(14) Rodnick J E, Dervin J V. Medical student clinics: the basis for a clerkship in Family Practice. fournal of Medical Education 1979 Apr; 54: 329-332.

(15) Levine C. Ethics and health cost containment. Hastings Center Report 1979 Feb: 10-13.

(16) Kleinberg W M, Gang M L, Gliebe W A. Costeffective medical practices: a curriculum at Medical College of Ohio. Ohio State Medical fournal 1979 May: 298-300.

(17) Cost awareness being added to Med Schools' curricula. Michigan Medicine I979 July: 386.

(18) Admundson L H et al. See reference (9).

(19) Schüffel W. Training in anger: how not to communicate with one's medical seniors. Biblio Psychiatry 1979; 159: 39-47.

(20) Silbert M V. Attitudes in the teaching of medical students. South African Medical fournal 1979 Mar; 24: 493 .

(2I) Coggan P G, Knight P, Davis P. Evaluating students in Family Medicine using simulated patients. Fournal of Family Practice 1980; 10/2: 259-265. 